\title{
Rachel Fell Mcdermott, Jeffrey J. Kripal (eds.), Encountering Kali in the Margins, at the Center, in the West
}

Berkeley-Los Angeles-Londres, University of California Press, 2003, XVIII + 322 p. (bibliogr., annexes, index)

\section{Francis Zimmermann}

\section{(2) OpenEdition}

\section{Journals}

Édition électronique

URL : http://journals.openedition.org/assr/870

DOI : $10.4000 /$ assr.870

ISSN : $1777-5825$

\section{Éditeur}

Éditions de l'EHESS

Édition imprimée

Date de publication : 1 octobre 2003

Pagination : 63-170

ISBN : 2-222-96739-2

ISSN : 0335-5985

\section{Référence électronique}

Francis Zimmermann, « Rachel Fell Mcdermott, Jeffrey J. Kripal (eds.), Encountering Kali in the Margins, at the Center, in the West », Archives de sciences sociales des religions [En ligne], 124 | octobre -

décembre 2003, document 124.33, mis en ligne le 16 novembre 2005, consulté le 24 septembre 2020. URL : http://journals.openedition.org/assr/870 ; DOI : https://doi.org/10.4000/assr.870 
prisonnière de l'éternelle discussion sur le voile, sa justification ou sa condamnation! Thème qui fait fi de leur contribution non seulement aux débats de la société mais à la formation d'un espace public.

Fariba Adelkhah.

MCDERMOTT (Rachel Fell), KRIPAL (Jeffrey J.), eds.

Encountering Kali in the Margins, at the Center, in the West. Berkeley-Los AngelesLondres, University of California Press, 2003, XVIII + 322 p. (bibliogr., annexes, index).

C'est depuis les années soixante-dix et sous l'influence du mouvement de la Contre-Culture que les Occidentaux, qu'ils s'intéressent au Tantrisme et aux cultes tantriques dans lesquels la Déesse représente la partenaire sexuelle du possédé, qu'ils soient spécialistes des sciences sociales associant l'anthropologie religieuse aux études féministes, ou bien encore, qu'ils soient engagés dans les croyances et les pratiques New Age, se sont passionnés pour l'étude de Kâlî, la déesse hindoue adorée à la fois sous la forme d'une guerrière assoiffée de sang et sous la forme d'une mère protectrice de tous les êtres. Cet ouvrage collectif, qui est issu d'un symposium organisé en 1996 au Department of Asian and Middle Eastern Cultures at Barnard College (New York) et dont les collaborateurs sont tous des indianistes de qualité, a pour ambition de faire le point sur le dossier de « la Déesse hindoue » au tournant du vingt-etunième siècle, en accordant une égale attention aux études indiennes proprement dites et aux études culturalistes appliquées à l'exportation et à la réception des représentations et des cultes de Kâlî en Occident. Le souci d'aborder systématiquement tous les aspects de la question en douze contributions est évident, puisque la table des matières est la suivante: trois études fondées sur la consultation des textes religieux (textes sanskrits ou bengalis), suivies de trois enquêtes de terrain (Orissa, Sri Lanka, Bénarès); puis deux chapitres relevant des postcolonial studies sur les images de Kâlî dans l'Inde britannique, un $9^{\mathrm{e}}$ chapitre sur Kâlî dans la tradition psychanalytique et le $10^{\mathrm{e}}$ sur la Shakti dans l'hindouisme antillais (Trinidad); deux cultural studies ferment la marche, l'une plaçant le féminisme au centre des cultes de la Déesse et l'autre explorant ses avatars sur internet. Ce sont des textes originaux, à l'exception du premier chapitre, repris à titre posthume du livre de David R. Kinsley, Hindu Goddesses: Visions of the Divine Feminine in the Hindu Religious Tradition (Berkeley,
University of California Press, 1986). Kinsley (1939-2000) était considéré en Amérique du nord comme le maître des études sur la Déesse hindoue, et la synthèse de seize pages sur Kâlî qui est ici réimprimée est assurément une bonne introduction à l'ensemble du dossier. Associés à ce souci d'exhaustivité, la bibliographie sélective, l'index et la filmographie donnée en appendice font de cet ouvrage un utile instrument de travail.

Il prête cependant à de sérieuses critiques. Les auteurs d'Encountering Kali ont presque tous oublié ou sciemment rejeté ce qui faisait la force et la fécondité des études indiennes à la génération précédente, à savoir la maîtrise des langues et des textes, un intérêt pour les institutions sociales, dans le cadre desquelles se développent les croyances et les pratiques, et l'étroite association de l'indologie classique avec les sciences sociales. L'ouvrage est donc très inégal et n'apporte que très peu de connaissances nouvelles, les données ethnographiques ou historiques sur lesquelles il repose étant le plus souvent citées de seconde main. La bibliographie est exclusivement anglo-américaine, ce qui est gênant si l'on veut bien reconnaître l'existence d'une littérature spécialisée publiée en Europe, qui ne cesse de s'enrichir depuis le livre collectif rassemblé sous la direction de Madeleine Biardeau, Autour de la déesse hindoue (Paris, Éditions de l'EHESS, 1981, [Coll. «Purushartha » $\mathrm{n}^{\circ}$ 5]). La comparaison entre ces deux dossiers réunis à vingt ans de distance sur le même sujet est d'ailleurs instructive. Madeleine Biardeau et ses collaborateurs français et américains, qui se passionnaient pour la Déesse hindoue, s'inscrivaient confusément dans le contexte de la ContreCulture et du féminisme comme le prouve la première phrase de cet ouvrage de 1981 : «Il y a dans l'air que respire l'indianiste depuis quelques années comme l'annonce d'une saison nouvelle. " Les thématiques de cette saison nouvelle ont depuis lors fleuri et Encountering Kali en 2003 engrange les moissons : déconstruction de l'imaginaire colonial, psychanalyse, diasporas hindoues des Amériques, New Age et mondialisation du culte de la déesse. Autant de thèmes désormais rebattus, qu'on ne faisait que pressentir au début des années quatre-vingt. De ce point de vue, l'ouvrage que nous recensons est un document à verser au dossier d'une histoire des idéologies contemporaines en Occident.

Francis Zimmermann. 